Jurnal Riset Agama

Volume 1, Nomor 2 (Agustus 2021): 247-258

DOI: $10.15575 /$ jra.v1i2.14526

https://journal.uinsgd.ac.id/index.php/jra

\title{
Hadis tentang Keutamaan Shalat Berjamaah
}

\author{
Muhammad Ilyas \\ Department of Hadith Science, Faculty of Usuluddin \\ UIN Sunan Gunung Djati Bandung \\ ilyasawesome17@gmail.com
}

\begin{abstract}
The purpose of this study is to discuss the traditions about the virtues of praying in congregation. This research method uses qualitative type through literature study using content analysis. The results and discussion of this study include general views of prayer in congregation, traditions about prayer in congregation, and the commandment of prayer and its virtues. The conclusion of this study is to find out how important prayer is in congregation, because prayer is the pillar of religion. Whoever establishes the prayer establishes his religion, and whoever abandons the prayer destroys his religion. This research is expected to be able to open up the views of parents so that in educating children it should not only be in terms of science, but must be accompanied by spiritual knowledge, one of which is prayer.
\end{abstract}

Keywords: Children; Congregational Prayer; Hadith; Syarah.

\begin{abstract}
Abstrak
Tujuan penelitian ini adalah membahas hadis-hadis tentang keutamaan shalat berjamaah. Metode penelitian ini menggunakan jenis kualitatif melalui studi pustaka dengan menggunakan analisis isi. Hasil dan pembahasan penelitian ini meliputi pandangan umum shalat berjamaah, hadis-hadis tentang shalat berjamaah, dan perintah shalat dan keutamaannya. Kesimpulan penelitian ini adalah mengetahui betapa pentingnya shalat berjamaah, karena shalat merupakan tiang agama. Barang siapa yang menegakkan shalat maka ia menegakkan agamanya, dan barang siapa yang meninggalkan shalat maka ia merobohkan agamanya. Penelitian ini diharapkan mampu membuka pandangan para orang tua agar dalam mendidik anak hendaknya tidak hanya dari segi keilmuan saja, tetapi harus dibarengi dengan pengetahuan kerohanian, salah satunya adalah shalat.
\end{abstract}

Kata kunci: Anak; Hadis; Shalat berjamaah; Syarah. 
Jurnal Riset Agama, Volume 1, Nomor 2 (Agustus 2021): 247-258

Muhammad Ilyas/Hadis tentang Keutamaan Shalat Berjamaah

\section{Pendahuluan}

Penerapan shalat berjamaah di masjid pada era millenial ini dirasa sangat kurang karena mereka disibukkan oleh kecanggihan teknologi sehingga adzan yang seharusnya menjadi pertanda untuk melakankan shalat wajib dianggap sebagai penanda biasa. Namun, di sisi lain kecanggihan teknologi menjadi sarana baru untuk menyebarkan syari'at Islam. Yang dahulunya harus bertatap muka sekarang bisa dilakukan dengan jarak jauh. Soulusi yang dapat dilakukan untuk penerapan shalat berjamaah di era millenial ini adalah menyadarkan ummat Islam bahwa shalat berjamaah merupakan bentuk ketaqwaan kepada Allah Swt. Sehinggga umat tidak tergolong sebagai orang yang menuhankan teknologi (Egziabher \& Edwards, 2013).

Sejumlah pakar telah melakukan penelitian berkenaan dengan keutamaan shalat berjamaah sebagaimana dalam tinjauan pustaka penelitian ini. Antara lain Nurhalin, Dede (1981), "Pemahaman Santri terhadap Keutamaan Salat Berjama'ah Hubungannya dengan Motivasi Pelaksanaan Salat Berjama'ah," Penerbit Universitas Islam Negeri Sunan Gunung Djati Bandung. Penelitian ini menggunnakan metode deskriptif. Pendekatan yang digunakan adalah pendekatan kualitatif dan kuantitatif. Hasil pembahasan dari skripsi ini adalah besarnya pengaruh pemahaman santri terhadab motivasi salat berjamaah adalah $11 \%$, artinya bahwa selain pemahaman, motivasi pelaksanaan salat berjamaah juga dipengaruhi oleh faktor lain, yaitu sebesar $89 \%$. Kesimpulan yang dapat diambil adalah motivasi hanya mempengaruhi sebagian kecil dalam pelaksanaan salat, sisanya banyak terdapat faktor-faktor yang lain (Maiti \& Bidinger, 1981). Satriani is, Sitti (2017), "Peranan Guru Pendidik Agama Islam dalam Membiasakan Siswa Sholat Berjama'ah," Penerbit Universitas Muhammadiah Makasar. Penelitian ini menggunakan metode deskriptif analitik. Hasil yang diperoleh adalah peranan seorang guru dalam membiasakan salat berjamaah melalui keteladanan samangat tinggi, sisanya adalah melalui pembiasaan dan pengawasan (Satriani, 2017). Budianto, Achmad (2020), "Implementasi Salat Dzuhur Berjamaah untuk Membentuk Akhlak Siswa di Madrasah Aliyah 2 Pamekasan," Penerbit Institut Agama Islam Negeri Madura. Penelitian ini menggunakan metode kualitatif. Hasil yang diperoleh adalah dalam pelaksaan salat berjamaah terdapat faktor pendukung dan penghambat. Faktor pendukungnya adalah terdapat dukungan dari guru untuk melaksanakan salat berjamaah, sedangkan faktor penghambatnya salah satunya adalah kurangnya kapasitas bangunan masjid (Budianto, 2020)

Berbagai penelitian terdahulu berhraga dalam penyusunan kerangka berpikir penelitian ini. Secara umum, salat berjamaah adalah salat yang dilakukan oleh dua orang atau lebih, dimana salah satunya menjadi imam dan yang lain menjadi makmum dengan memenuhi semua ketentuan salat 
berjamaah (Kurniati, 2017). Untuk melakukan salat berjamaah, sebenarnya tidak sekedar berjamaah secara minimalis terdiri dari dua orang begitu saja, melainkan ada beberapa kriteria yang bersumber dari contoh aplikatif di masa Nabi SAW (Kurniati, 2017). Salat adalah suatu ibadah yang dilakukan dengan anggota lahir dan batin dalam bentuk gerakan dan ucapan tertentu (Darussalam, 2016). Salat jama'ah lebih utama dua puluh tujuh derajat daripada salatnya seorang laki-laki sendirian (MAYRA, 2013). Bila seorang dari kalian melakukan salat bersama orang-orang (menjadi imam), maka ringankanlah karena di kalangan mereka ada yang sakit, yang lemah, dan yang sudah tua. Tetapi jika salah seorang dari kalian salat sendirian, maka ia boleh memperpanjang sekehendaknya (Siregar, 2016). Sempurnakanlah saf pertama, kemudian saf berikutnya. Kalaupun ada saf yang kurang (saf yang tidak mencukupi), maka hendaklah disaf yang paling belakang (MAYRA, 2013). Perintahkan anak-anak mengerjakan shalat jika sudah berumur tujuh tahun (Hermawan, 2019). Ajarilah anak-anak shalat ketika sudah berumur tujuh tahun dan pukullah mereka karena meninggalkan shalat jika mereka sudah berumur sepuluh tahun (Hermawan, 2019). Perintahkanlah anak-anak yang sudah berumur tujuh tahun. Dan pukulah mereka karena meninggalkannya ketika telah berumur 10 tahun. Serta pisahkanlah mereka dalam tempat tidur mereka (Hermawan, 2019).

Berdasarkan paparan di atas, penulis berusaha menyusun formula penelitian, yaitu rumusan masalah, pertanyaan penelitian, dan tujuan penelitian (Darmalaksana, 2020). Rumusan masalah penelitian ini adalah terdapat penjelasan hadis tentang keutamaan salat berjamaah. Pertanyaan utama penelitian ini ialah bagaimana penjelasan hadis tentang keutamaan salat berjamaah. Sedangkan pertanyaan secara terperinci yaitu bagaimana pandangan umum tentang salat berjamaah, bagaimana hadis-hadis tentang salat berjamaah, dan bagaimana perintah salat dalam hadis serta keutamaannya. Tujuan penelitian ini yakni menjelaskan keutamaan salat berjamaah menurut hadis. Penelitian ini diharapkan memiliki manfaat bagi pengayaan khazanah pengetahuan Islam.

\section{Metode Penelitian}

Penelitian ini merupakan jenis kualitatif melalui studi pustaka dengan analisis isi (Gunawan, 2013).

\section{Hasil dan Pembahasan}

Hasil dan pembahasan penelitian di bawah ini.

\section{Pandangan Umum Shalat Berjamaah}

Kata shalat berakar dari Bahasa Arab yaitu صلي-يصلي-صلاة yang artinya adalah doa. Sedangkan menurut bahasa terdapat dua pengertian, yaitu "berdoa" dan "bersholawat." Shalat menurut bahasa adalah doa, 
Jurnal Riset Agama, Volume 1, Nomor 2 (Agustus 2021): 247-258

Muhammad Ilyas/Hadis tentang Keutamaan Shalat Berjamaah

sebagaimana firman Allah Swt dalam surah At -Taubah ayat 103 yang berbunyi:

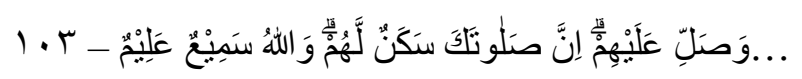

Dan doa-kanlah untuk mereka. Sesungguhnya doa kamu itu (menjadi) ketentraman jiwa bagi mereka. Dan Allah Maha mendengar lagi Maha Mengetahui (QS. At-Taubah:103). Sedangkan menurut istilah shalat merupakan suatu ibadah yang mengandung perkataan dan perbuatan tertentu yang dimulai dengan takbir disudahi dengan salam. Jemaah menurut bahasa diambil dari kata jama' artinya mengumpulkan sesuatu dengan mendekatkan sebagian dengan sebagian lainnya. Jemaah adalah sekelompok orang banyak dan dikatakan juga sekelompok manusia yang berkumpul berdasarkan suatu tujuan. Al-jama'ah menurut istilah fuqaha merupakan bilangan manusia yang berjumlah banyak. Al-Kasani berkata "Al-Jama"eah terambil dari kata "alijtima". Jumlah terkecil sebuah jemaah adalah terdiri dari dua orang, yaitu antara imam dan makmum. Secara umum shalat berjamaah artinya shalat yang dilakukan kaum muslimin secara bersama-sama yang sedikit-dikitnya dari dua orang, yaitu satu orang sebagai imam dan satu orang lagi sebagai makmun. Ketika melaksanakan shalat berjamaah maka posisi imam di depan dan makmum berada di belakang, seorang makmum juga harus mengikuti gerakan imam dan tidak boleh mendahuluinya. Sebagaimana sabda Nabi yang artinya: Telah menceritakan kepada kami Musaddad berkata, telah menceritakan kepada kami Yazid bin Zurai' berkata, telah menceritakan kepada kami Khalid AlHadzdza' dari Abu Qilabah dari Malik bin Al-Huwairits dari Nabi shallallahu 'alaihi wasallam, beliau bersabda: "Jika telah datang waktu shalat maka adzan dan iqamatlah, kemudian hendaklah yang mengimami shalat adalah yang paling tua di antara kalian berdua (HR. Bukhari) (Kurniati, 2017).

Shalat berjamaah adalah salah satu simbol kebersamaan umat muslim, shalat jamaah mendapatkan pahala 27 derajat lebih baik jika dibandingkan dengan shalat yang dilakukan sendirian. Dalam shalat berjamaah memiliki ikatan ketergantungan antara shalat makmum kepada shalat imam. Dalam melaksanakan shalat berjamaah, perlu diperhatikan beberapa hal mengenai keimanan dan kemakmuman, yakni Islam, berakal, adil, baligh, yang menjadi imam untuk jamaah sebaiknya orang yang faqih atau yang lebih tau atau lebih baik bacaannya dan bisa menjadi imam di antara jamaah yang lain, perempuan tidak diperbolehkan menjadi imam bagi laki-laki tetapi diperbolehkan menjadi imam apabila semua jamaahnya adalah seorang perempuan, makmum tidak menempatkan dirinya di depan imam, berkumpul dalam satu tempat tanpa penghalang, berniat, shalat makmum dan imam harus sama, bacaan yang sempurna. Di 
samping itu, dalam pelaksanaan shalat berjamaah, terdapat syarat-syarat yang harus dipahami terlebih dahulu, yaitu makmum diwajibkan meniatkan mengikutkan imam dan imam tidak diwajibkan berniat menjadi imam hanya sunat agar ia mendapatkan ganjaran berjamaah, makmum wajib mengikuti imamnya dalam melaksanakan shalat, mengetahui gerakgerik perbuatan imam, imam hendaknya berpendirian tidak terpengaruh oleh orang lain, dan janganlah makmum beriman kepada orang yang diketahui bahwa shalatnya tidak sah atau batal. Selain syarat-syarat, shalat berjamaah juga memiliki beberapa kemuliaan, di antaranya ialah shalat berjamaah lebih utama 27 derajat dibanding dengan shalat sendiri, Allah akan menuliskan kebaikan, mengangkat derajat, dan menghapus dosanya, malaikat memberi shalawat kepada orang yang shalat berjamaah, pahala orang yang keluar untuk mengerjakan shalat sama dengan pahala orang yang menunaikan ibadah haji yang berihram, tetap mendapatkan shalat berjamaah meskipun masbuk (terlambat datang), dan pahalanya lebih besar dari pada shalat sendirian (MAYRA, 2013).

Secara definitif, sahalat terbagi menjadi dua macam, pertama dilihat dari sudut batiniah dan kedua sudut lahiriah. Dari sudut batiniyah shalat yakni menumbuhkan di dalam hati rasa keagungan dan kebesaran-Nya dan menghadapkan hati kepada Allah SWT yang mendatangkan takut kepada-Nya. Dari sudut lahiriyah dikemukakan oleh ahli fiqih, shalat adalah ibadah yang terdiri dari perbuatan (gerakan) dan perkataan (ucapan tertentu) yang dimulai dengan takbir dan diakhiri dengan salam. Namun ada pendapat yang menggabungkan kedua definisi tersebut, sehingga dapat disimpulkan bahwa shalat ialah ibadah yang dilakukan dengan anggota lahir dan batin dalam bentuk gerakan dan ucapan tertentu yang sesuai dengan arti shalat yaitu melahirkan niat (keinginan) dan keperluan seorang umat kepada Allah Tuhan yang disembah, dengan perbuatan (gerakan) dan perkataan yang keduanya dilakukan secara bersamaan. Sedangkan menurut T.A Lathief Rousydy yang dikutip oleh Riznanto dan Rahmawati, definisi shalat terbagi menjadi 3 (tiga) yakni: pertama, menurut hakikatnya shalat ialah mengahadapkan jiwa kepada Allah dengan cara mendatangkan rasa takut dan membangkitkan rasa kagum di dalam hati atas kebesaran-Nya dan kesempurnaan kekuasaan-nya. Kedua, menurut bentuk, sifat dan kaifiyahnya shalat ialah perkataan dan perbauatan yang dimulai dari takbir dan diakhiri oleh salam, dengan cara Tuhan disembah disertai dengan cara-cara tertentu. Ketiga, menurut ruh atau jiwanya shalat ialah mengahadap Allah dengan sepenuh jiwa dan khusyue di hadapanNya serta ikhlas kepada-Nya disertai dengan ketulusan hati dalam berdzikir, berdoa dan memuji (Islam et al., 2020). 


\section{Hadis-Hadis tentang Shalat Berjamaah}

Terdapat Hadis Nabi Saw. Berkaitan dengan shalat berjamaah dalam kitab Shahih Bukhari Nomor 662:

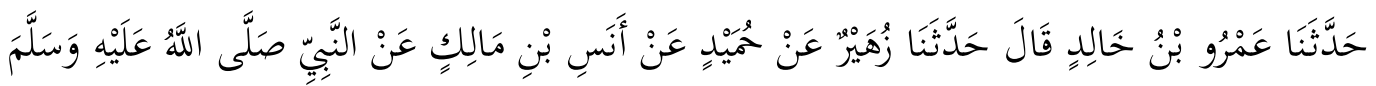

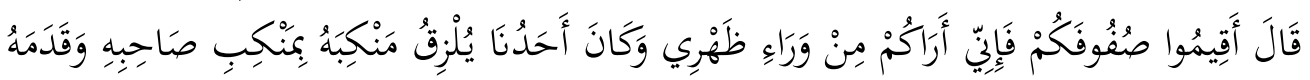

$$
\begin{aligned}
& \text { بِقَدَمِِِ }
\end{aligned}
$$

Telah menceritakan kepada kami 'Amru bin Khalid berkata, telah menceritakan kepada kami Zuhair dari Humaid dari Anas bin Malik dari Nabi shallallahu 'alaihi wasallam, beliau bersabda: "Luruskanlah shaf-shaf kalian, sesungguhnya aku dapat melihat kalian dari balik punggungku." Dan setiap orang dari kami merapatkan bahunya kepada bahu temannya, dan kakinya pada kaki temannya" (HR. Bukhari).

Mula-mula dilakukan pencarian melalui aplikasi hadis dengan kata kunci "shalat" sehingga ditemukan hadis pada kitab Shahih Bukhari Nomor 662, sebagaimana dikemukakan terdahulu.

Tabel 1 Daftar Rawi Sanad

\begin{tabular}{|c|c|c|c|c|c|c|}
\hline \multirow{2}{*}{ No. } & \multirow{2}{*}{$\begin{array}{c}\text { Rawi } \\
\text { Sanad } \\
\end{array}$} & Lahir/Wafat & \multirow{2}{*}{ Negeri } & \multirow{2}{*}{ Kuniyah } & Komentar Ulama & \multirow{2}{*}{ Kalangan } \\
\hline & & $\mathbf{L} \quad \mathbf{W}$ & & & $-\quad+$ & \\
\hline 1 & $\begin{array}{l}\text { Anas bin } \\
\text { Malik bin } \\
\text { An Nadlir } \\
\text { bin } \\
\text { Dlamdlom } \\
\text { bin Zaid } \\
\text { bin Haram }\end{array}$ & $91 \mathrm{H}$ & Bashrah & $\begin{array}{l}\text { Abu } \\
\text { Hamzah }\end{array}$ & -Sahabat & Sahabat \\
\hline 2 & $\begin{array}{l}\text { Humaid } \\
\text { bin Abi } \\
\text { Humaid }\end{array}$ & $142 \mathrm{H}$ & Basharah & $\begin{array}{l}\text { Abu } \\
\text { 'Uibaidah }\end{array}$ & $\begin{array}{l}\text { - Tsiqah } \\
\text { - Tsiqah } \\
\text { - Tsiqah } \\
\text { - Shaduuq } \\
\text { - Tsiqah la } \\
\text { ba'sabih } \\
\text { - Tsiqah } \\
\text { Mudallas }\end{array}$ & $\begin{array}{l}\text { Tabi'in } \\
\text { kalangan } \\
\text { biasa }\end{array}$ \\
\hline 3 & $\begin{array}{l}\text { Zuhair bin } \\
\text { Mu'awiyah } \\
\text { bin Hudaij }\end{array}$ & $173 \mathrm{H}$ & Kufah & $\begin{array}{l}\text { Abu } \\
\text { Khaitsamah }\end{array}$ & $\begin{array}{l}\text {-Tsiqah } \\
\text {-Tsiqah } \\
\text { Tsabat } \\
\text { - Tsiqah } \\
\text { - } \\
\text { disebutkan }\end{array}$ & $\begin{array}{l}\text { Tabi'in } \\
\text { kalangan } \\
\text { tua }\end{array}$ \\
\hline
\end{tabular}




\begin{tabular}{|c|c|c|c|c|c|c|}
\hline & & & & & $\begin{array}{l}\text { dalam 'ats } \\
\text { tsiqaat } \\
\text { - Alhafidz } \\
\text {-Tsiqah } \\
\text { Hujjah }\end{array}$ & \\
\hline 4 & $\begin{array}{l}\text { Amru bin } \\
\text { Khalid bin } \\
\text { Farrukh } \\
\text { bin Sa'id }\end{array}$ & $229 \mathrm{H}$ & Jazirah & $\begin{array}{l}\text { Anu Al } \\
\text { hasan }\end{array}$ & $\begin{array}{l}\text { - Shaduuq } \\
\text {-Tsiqah } \\
\text {-Tsiqah } \\
\text {-Tsiqah } \\
\text { - } \\
\text { disebutkan } \\
\text { dalam 'ats } \\
\text { tsiqaat } \\
\text {-Tsiqah }\end{array}$ & $\begin{array}{l}\text { Tabi'ut } \\
\text { Tabi'in } \\
\text { kalangan } \\
\text { tua }\end{array}$ \\
\hline
\end{tabular}

Tabel 1 adalah daftar rawi dan sanad dari hadis yang akan di teliti. Pemaparan para periwayat telah disusun secara urut, dari periwayat pertama hingga akhir. Hal ini dilakukan agar para pembaca tidak kesulitan dan mudah memahami posisi dan susunan para periwayat. Dalam ilmu hadis para periwayat hadis disebut sebagai rawi, sedangkan sanad merupakan rangkaian para perawi hadis. Sebuah hadis dapat dikatakan sebagai hadis shahih apabila telah telah terverifikasi para perawinya dengan baik, mengikuti standar yang telah ditetapkan oleh para kritikus hadis (Muzayyin, 2017). Sebuah hadis dinyatakan tidak memiliki kekurangan atau dinyatakan valid apabila para periwayat yang meriwayatkan hadis tersebut bernilai positif menurut komentar para ulama disertai dengan ketersambungan transmisi menurut tahun kelahiran periwayat. Apabila text hadis dimengrti menurut akal sehat dan tidak bertentangan dengan al-Qur'an, maka hadis tersebut tidak membutuhkan validasi untuk dikategorikan sebagai amal kebaikan (Mohammad Fajar Septian1, Wahyudin Darmalaksana2,Mulyana3, 2021). Syarat hadis dinyatakan shahih juga adalah sanadnya bersambung, jika ditemukan sanadnya terputus, maka hadis tersebut temasuk hadis dhaif. Bukti sanad tersambung adalah bertemunya guru dan murid (Muzayyin, 2017).

Syarah hadis telah dilakukan para ulama sejak zaman klasik dengan berbagai pendekatan (Mohammad Fajar Septian1, Wahyudin Darmalaksana2,Mulyana3, 2021). Hadis di atas menggambarkan salah satu tata cara melaksanakan shalat, yaitu meluruskan dan merapatkan shaf shalat. Saat ini, banyak ditemukan dikalangan masyarakat dalam pelaksanaan sahalat tidak menginindahkan makna hadis di atas. Hal tersebut terjadi karena tolak ukur masyarakat tentang meluruskan dan merapatkan shaf shalat adalah bentangan sajadah yang dibawa. Jika berpatokan dengan bentangan sajadah akan ada celah kosong, celah 
tersebut menandakan bahwa kita menyediakan tempat untuk para setan. Sebagaimana dijelaskan dalam sabda Rasul:

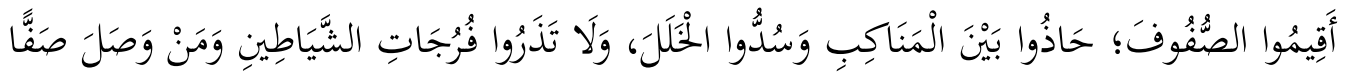

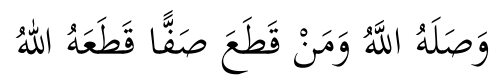

“Luruskanlah shaf kalian. Sejajarkanlah pundak-pundak kalian. Tutuplah celah. Janganlah kalian membiarkan ada celah untuk syaitan. Barangsiapa yang menyambung shaf, maka Allâh k akan menyambung hubungan dengannya dan barangsiapa memutus shaf maka Allâh akan memutuskan hubungan dengannya" (HR. Abu Dawud No. 666).

Diakui secara sadar atau tidak, meluruskan dan merapatkan shaf ketika shalat memiliki berbagai aspek pendidikan dan moral. di antaranya adalah:

a. Sebagai pemersatu

Berkumpulnya kaum muslimin tidak peduli siapa di kanan-kiri kita, entah dari bangsa atau suku manapun akan bersatu dan tidak akan ada jarak. Hal tersebut menjadi bukti bahwa shalat dengan merapatkan shaf menjadi pemersatu dalah menghadap kepada Allah swt.

b. Menciptakan persamaan antar sesama manusia

Bahwa semua jamaah berada dalam taraf yang sama. Entah kaya, miskin, tuan, budak, bangsawan tidak ada bedanya ketika dihadapan Allah swt kecuali dalam hal ketakwaannya.

Itulah dalil-dalil yang menyatakan untuk meluruskan dan merpatkan shaf ketika shalat berjamaah. Karena meluruskan dan merapatkan merupakan kesempurnaan shalat (Fitria, 2013).

\section{Perintah Shalat dan Keutamaannya}

Menurut ajaran Islam, manusia dilahirkan dalam keadaaan tanpa memiliki pengetahuan apapun. Hal tersebut sejalan dengan makna ayat alQuran yang terdapat pada surat An-Nahl ayat 78:

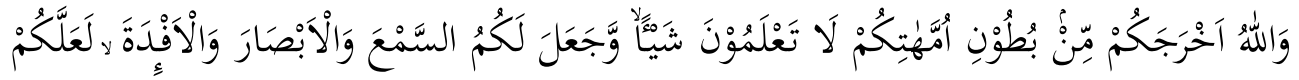

$$
\begin{aligned}
& 78 \text { تَشْكُوُوْْونَ }
\end{aligned}
$$


"Dan Allah mengeluarkan kamu dari perut ibumu dalam keadaan tidak mengetahui sesuatu pun, dan Dia memberimu pendengaran, penglihatan, dan hati nurani, agar kamu bersyukur' (An-Nahl: 78).

Meskipun demikian, Allah swt tidak semerta-merta membiarkan kita dalam keadaan tersebut. Allah swt memberi bekal kepada kita berupa potensi untuk mengembangkan diri sehingga menjadi pribadi seperti yang di katakana Rasulullah saw yaitu khalifah dimuka bumi. Hal tersebut yang perlu diperhatikan orang tua dalam mengasuh anaknya (Atmojo, 2018). Orang tua memiliki peran sangat sentral dalam mendidik anak karena menjadi madrasah pertama. Melalui keluarga anak belajar, tumbuh dan berkembang. Orang tua juga harus mengetahui aspek-aspek perkembangan anak sehingga dapat memberikan stimulasi yang tepat kepada anak, termasuk pula membiasakan terhadap hal-hal yang berkaitan dengan keagamaan seperti halnya shalat (Khairi, 2020).

Shalat merupakan suatu kewajiban yang harus dilakukan oleh orang yang beragama Islam tanpa membeda-bedakan ras, warna kulit, kedudukan, tua, muda bahkan anak-anak sekalipun. Kewajiban mengajarkan shalat kepada anak yang dalam hal usia belum mencapai umur sangat diperlukan. Hal tersebut dilakukan sebagi upaya pembiasaan terhadap anak ketika nanti dirinya diwajibkan melaksanakan shalat agar tidak kaget dan sudah terbiasa. Perintah shlat kepada anak juga telah dijelaskan dalam hadis Nabi saw:

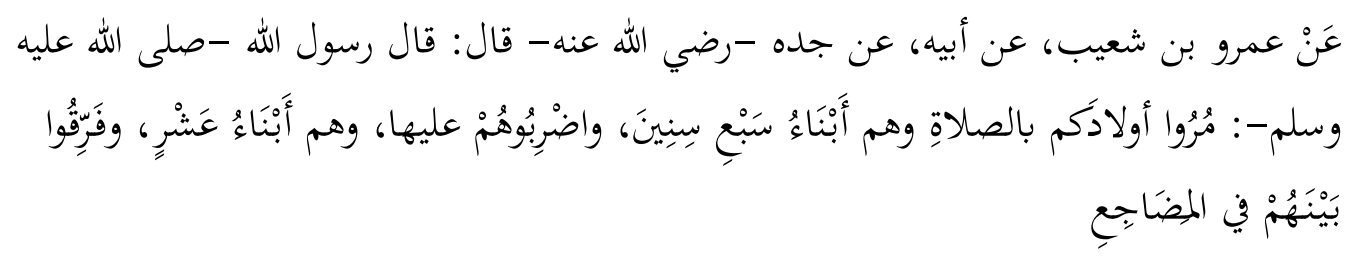

Dari Amr Bin Syu'aib dari ayahnya dari kakeknya berkata: "Rasulullah SAW bersabda: "Perintahkan anak-anakmu melaksanakan sholat sedang mereka berusia tujuh tahun dan pukullah mereka karena tinggal sholat sedang mereka berusia 10 tahun dan pisahkan antara mereka di tempat tidurnya" (Hadis hasan. Diriwayatkan oleh Abu Dawud dengan sanad yang Hasan).

Dari hadis di atas, hendaknya para orang tua mendidik serta mengajarkan thaharah dan shalat kepada anak-anak mereka sedari kecil. Bahkan meskipun umur mereka belum menginjak tujuh tahun. Ketika anak sudah menginjak akil baligh atau telah mimpi basah untuk laki-laki dan haid untuk perempuan orangtua diperbolehkan memukul anaknya jika lalai atau tidak mengerjakan shalat. Pukulan yang dimaksudkan adalah pukulan yang mendatangkan manfaat dan tidak melukai. Dan dihindarkan 
memukul bagian wajah dan dada, karena hal tersebut tidak diperbolehkan (Hermawan, 2019).

Shalat pada hakikatnya merupakan sebuah komunikasi dua arah antara hamba dan tuhannya. Hal tersebut tergambarkan dari dialog-dialog yang dilantunkan ketika shalat. Meskipun secara lahiriah yang dirasakan oleh orang yang melaksanakan shalat adalah intra persona, artinya ia berbicara dengan dirinya sendiri. Maka dari itu komunikasi yang terjalin antara hamba dan tuhannya ketika pelaksanaan shalat merupakan komunikasi transidental (Bachtiar, 2014).

Selain perintah shalat yang dianjurkan, ternyata sahalat memiliki banyak keutamaan. Sa'id bin Ali bin Wahaf al Qahthani menyebutkan beberapa keutamaan shalat berjamaah dalam panduan shalat lengkapnya. Yaitu sebagai berikut:

a. Shalat jamaah dua puluh tujuh kalilipat dari shalat sendirian.

b. Dengan shalat jamaah, akan melindungi pelakunya dari setan.

c. Keutamaan shalat akan bermbah seiring banyaknyanya jumlah makmum.

d. Kebebasan dari api neraka dan kemunafikan bagi barang siapa yang melaksanakan shalat berjamaaah selama empat puluh hari tanpa bolong.

e. Barang sipa shlat subuh berjamaah, dia berada dalam jaminan dan perlindungan Allah swt sampai waktu sore.

f. Paling besarnya pahala shalat adalah shalat isya' dan subuh secara berjamaan $(\mathrm{F}, 1967)$.

\section{Kesimpulan}

Sebagai seorang muslim, hendaknya meneggakkan nilai-nilai keagamaan yang tercantum dalam rukun Islam, sakah satunya adalah shalat. Shalat memiliki peran sentral nomer dua setelah syahadad. Hal tersebut menandakan bahwa shalat memiliki andil sangat besar dalam perjalanan seorang manusia dalam menegakkan agamanaya. Seprti sabda Nabi yang artinya "shalat itu merupakan tiang agama, barangsiapa mendirikan shalat maka ia mendirikan agamanya, dan barangsipa meninggalkannya maka ia merobohkan agamanya.' Shalat juga hendaknya diajarkan kepada anak-anak semenjak mereka masih kecil. Hal tersebut bertujuan sebagai pembiasaan terhadap pelaksanaan shalat, seperti halnya dengan puasa. Hendaknya bagi para orang tua sangat memperhatikan maslah ini dalam pendidikan kepada anak-anaknya. Karena madrasah pertama bagi anak adalah kedua orang tua mereka. Dalam penelitian ini, penulis mengakui masih jauh dari kata sempurna karena memiliki banyak keterbatasan. Sehingga masih dibutuhkan penelitian lebih lanjut agar dapat menompang kekurangan yang terdapat saat ini. 
Jurnal Riset Agama, Volume 1, Nomor 2 (Agustus 2021): 247-258

Muhammad Ilyas/Hadis tentang Keutamaan Shalat Berjamaah

\section{Daftar Pustaka}

Atmojo, H. (2018). Analisis hadits tentang perintah shalat pada anak dalam sunan abu daud. IAIN Palangkaraya.

Bachtiar, E. (2014). Shalat sebagai Media Komunikasi Vertikal Transendental. Konseling Religi : Jurnal Bimbingan Konseling Islam, 5(2), 385-400.

Budianto, A. (2020). Implementasi Shalat Dhuhur Berjamaah untuk Membentuk Akhlak Siswa di Madrasah Aliyah Negeri 2 Pamekasan. Rabbani: Jurnal Pendidikan Agama Islam, 1(1), 11-26.

Darmalaksana, W. (2020). Formula Penelitian Pengalaman Kelas Menulis. Jurnal Kelas Menulis UIN Sunan Gunung Djati Bandung.

Darussalam, A. (2016). Indahnya Kebersamaan dengan Shalat Jamaah. Tafsere, 4(1), 24-39.

Egziabher, T. B. G., \& Edwards, S. (2013). 済無No Title No Title. Africa's Potential for the Ecological Intensification of Agriculture, 53(9), 1689-1699.

F, K. Ge. (1967). 済無No Title No Title No Title. Angewandte Chemie International Edition, 6(11), 951-952.

Fitria. (2013). 済無No Title No Title. Journal of Chemical Information and Modeling, 53(9), 1689-1699.

Gunawan, I. (2013). KUALITATIF Imam Gunawan. Pendidikan, 143.

Hermawan, R. (2019). Pengajaran Sholat Pada Anak Usia Dini Perspektif Hadis Nabi Muhammad Saw. INSANIA : Jurnal Pemikiran Alternatif Kependidikan, 23(2), 282-291. https:/ / doi.org/10.24090/insania.v23i2.2301

Islam, U., Sultan, N., Kasim, S., Memenuhi, U., \& Syarat, S. (2020). Pengaruh Perceraian Orang Tua Terhadap Perkembangan Psikis Anak Di Desa Pulau Payung Kecamatan Rumbio Jaya Kabupaten Kampar. Universitas Islam Negeri Sultan Syarif Kasim Riau.

Khairi, K. (2020). Keluarga sebagai Madrasah Pertama Anak (Memaksimalkan Peran Orang Tua dalam Perkembangan Anak Usia 1-4 Tahun, TA 2019/2020). Mitra Ash-Shibyan: Jurnal Pendidikan Dan Konseling, 03(02), 106-117.

Kurniati, V. (2017). Halaman 1 dari 67 muka | daftar isi. 1-35.

Maiti, \& Bidinger. (1981). 済無No Title No Title. Journal of Chemical Information and Modeling, 53(9), 1689-1699.

MAYRA, G. (2013). Strategi Komunikasi Guru BK Dalam Membentuk Karakter Positif Siswa SMANegeri 4 Makassar. Journal of Chemical Information and Modeling, 53(9), 1689-1699.

Mohammad Fajar Septian1, Wahyudin Darmalaksana2,Mulyana3, M. F. (2021). Gunung Djati Conference Series, Volume 1 (2021) Conference on Islamic and Socio-Cultural Studies (CISS 2020). 1, 155-160.

Muzayyin, A. (2017). Kualitas Hadis Ditentukan Oleh Kualitas Terendah 
Jurnal Riset Agama, Volume 1, Nomor 2 (Agustus 2021): 247-258

Muhammad Ilyas/Hadis tentang Keutamaan Shalat Berjamaah

Rawi Dalam Sanad. Jurnal Al-Muta'aliyah STAI Darul Kamal NW Kembang Kerang, I(1), 237-244.

Satriani, S. (2017). Peranan guru PAI dalam membiasakan siswa shalat berjamaah. Jurnal Tarbawi, 2(1), 33-42.

Siregar, D. (2016). Analisis Hadis-Hadis Tentang Fadilah Shalat Berjamaah. Yurisprudentia: Jurnal Hukum Ekonomi, 2, 16-39. 